\title{
Persepsi Mahasiswa terhadap Pelayanan Program Studi PPKn
}

\author{
Zola Oktavia, Hasrul \\ Jurusan Ilmu Sosial Politik \\ FIS Universitas Negeri Padang \\ E-mail: zolaoktavia055@gmail.com
}

\section{ABSTRAK}

Penelitian ini bertujuan untuk mengetahui persepsi mahasiswa terhadap pelayanan program studi PPKn FIS UNP dilihat dari aspek berwujud (tangible), keandalan (reliability), daya tanggap (responsivenese), kepastian (assurance), dan empati (emphaty) guna dijadikan gambaran atau pedoman untuk pelayanan program studi PPKn FIS UNP lebih baik lagi kedepannya. Metode yang digunakan dalam penelitian ini yaitu deskriptif dengan pendekatan kuantitatif. Penelitian ini dilakukakn dengan menyebar angket kepada mahasiswa melalui google form. Sampel dalam penelitian ini sebanyak 37 mahasiswa. Jenis data yang digunakan yaitu data primer dan sumber datanya mahasiswa program studi PPKn FIS UNP angkatan 2017, 2018, dan 2019 yang dijadikan sampel. Instrumen penelitian yang digunakan adalah angket dengan skala likert menggunakan alternatif jawaban Sangat Baik (SB), Baik (B), Cukup Baik (CB), dan Kurang Baik (KB). Hasil penelitian menunjukkan bahwa persepsi mahasiswa terhadap pelayanan akademik dikategorikan baik dengan persentase 83,25\% dan pelayanan administrasi dikategorikan baik dengan persentase yang sama yaitu 83,25\%. Sehungga dapat diketahui bahwa persepsi mahasiswa terhadap program studi PPKn FIS UNP dikategorikan baik dengan rata-rata persentase 83,25\%.

Kata Kunci: aspek pelayanan, program studi, mahasiswa

\section{ABSTRACT}

This study aims to determine students' perceptions of service study program PPKn FIS UNP seen from the aspect of intangible (tangible), reliability (reliability), responsiveness (responsivenese), assurance (assurance), and empathy (empathy) to be used as illustration or guidelines for service PPKn FIS UNP study programs are better in the future. The method used in this research is descriptive with a quantitative approach. This research was conducted by distributing questionnaires to students through Google form. The sample in this study were 37 students. The type of data needed is primary data and the data sources are PPKn FIS UNP study programs for the 2017, 2018, and 2019 batches as samples. The research instrument used was a tie with a Likert scale using the alternative answers Very Good (SB), Good (B), Fairly Good (CB), and Less Good (KB). The results showed that students' perceptions of academic services were categorized 
well with a percentage of $83.25 \%$ and administrative services categorized well with the same percentage of $83.25 \%$. So that it can be seen that students' perceptions of the PPKn FIS UNP study program are categorized as good with an average percentage of $83.25 \%$

Keywords: service aspects, study program, students.

This work is licensed under the Creative Commons Attribution-ShareAlike 4.0 International License. ( 2020 by author.

\section{PENDAHULUAN}

Peran pendidikan dalam kehidupan dewasa ini sangatlah penting, tingkat persaingan dan kebebasan juga semakin meningkat terutama dalam bidang pendidikan tinggi. Perguruan tinggi sebagai wadah yang strategis diharapkan mampu untuk menghasilkan sumber daya manusia yang bermutu dan mampu bersaing dalam dunia kerja baik dalam maupun luar negeri. Persaingan yang semakin ketat antar perguruan tinggi menuntut lembaga pendidikan untuk memperhatikan mutu pendidikan dan kelembagaannya agar mampu unggul dalam persaingan tersebut. Dengan demikian perguruan tinggi harus meningkatkan aspek pelayanan yang dimiliki untuk menghadapi persaingan yang semakin ketat tersebut.

Salah satu kunci untuk memenangkan persaingan dalam dunia pendidikan tinggi di era globalisasi saat ini adalah berusaha meningkatkan rasa kepuasan konsumen terhadap jasa atau layanan yang diberikan oleh pihak perguruan tinggi kepada mahasiswa (Tjiptono dalam Udjang, R \& Subarjo 2009:65). Selanjutnya menurut Simonson (dalam Udjang, R 2009:65) agar dapat memenangkan persaingan perlu memenuhi apa yang diinginkan oleh mahasiswa. Kesesuaian antara keinginan atau persepsi konsumen (customer voice) dan keinginan organisasi pengelola/perguruan tinggi (company voice) merupakan syarat penting dalam keberhasilan proses pendidikan (Muafi dan Siswanti dalam Husnayetti, 2012:115). Standar minimum pelayanan pada perguruan tinggi dirumuskan dengan Standar Pelayanan Minimum (SPM). SPM yaitu, spesifikasi teknis tentang tolak ukur layanan minimum yang diberikan oleh perguruan tinggi kepada masyarakat dengan mempertimbangkan kualitas layanan, pemerataan, kesetaraan layanan, biaya, dan kemudahan untuk mendapatkan layanan (Peraturan Menteri Pendidikan Nasional No. 53 Tahun 2008) (dalam Darwyansyah 2014:21).

Di lingkungan Program Studi Pendidikan Pancasila dan Kewarganegaraan (PS-PPKn), mahasiswa merupakan pihak yang langsung terlibat dalam proses pelayanan yang dilaksanakan suatu institusi pendidikan. Pelayanan jasa dilingkungan program studi yang baik harus memperhatikan faktor penentu mutu jasa pelayanan yaitu

1. Berwujud (tangible), yaitu berupa penampilan fasilitas fisik, peralatan dan berbagai materi komunikasi.

2. Keandalan (reliability), yaitu kemampuan dosen/staf administrasi dan pengurus program studi untuk memberikan jasa sesuai dengan yang 
dijanjikan, terpercaya, akurat dan konsisten.

3. Daya tanggap (responsivenese), yaitu kemampuan dari dosen/staf administrasi dan pengurus program studi membantu mahasiswa dan memberikan jasa dengan cepat dan bermakna serta kesediaan mendengar dan mengatasi keluhan yang diajukan.

4. Kepastian (assurance), yaitu kemampuan dari dosen/staf administrasi dan pengurus program studi untuk menimbulkan keyakinan dan kepercayaan terhadap janji yang telah dikemukakan kepada mahasiswa.

5. Empati (emphaty), yaitu kesediaan dosen/staf administrasi dan pengurus program studi untuk lebih peduli dan memberikan perhatian secara pribadi kepada mahasiswa.

Namun, saat peneliti melakukan wawancara dengan beberapa mahasiswa program studi PPKn FIS UNP serta pengamatan peneliti dilapangan mereka mengeluhkan beberapa hal seperti :

1. Berwujud (tangible) : ruang baca yang kadang hanya dijadikan tempat bercerita dan mencari wifi oleh mahasiswa.

2. Keandalan (reliability) : dosen datang dan pulang tidak sesuai dengan jadwal yang telah ditentukan.

3. Daya tanggap (responsivenese) : dosen pembimbing akademik kadang sulit untuk ditemui.

4. Kepastian (assurance) : dosen tidak obyektif dalam memberikan penilaian.

5. Empati (emphaty) : staf administarsi kadang cuek dalam merespon keperluan mahasiwa.

Oleh karena perlu dilakukannya penelitian agar mengetahui bagaimana sebenarnya persepsi mahasiswa terhadap pelayanan program studi PPKn FIS UNP, dengan tujuan untuk meningkatkan mutu pelayanan program studi PPKn FIS UNP.

\section{METODE}

Jenis penelitian ini yaitu penelitian "deskriptif" dengan pendekatan "kuantitatif". Statistik deskriptif berfungi untuk memberikan gambaran terhadap obyek yang diteliti melalui data sampel atau populasi. Sampel dalam penelitian ini sebanyak 37 mahasiswa dari 362 populasi mahasiswa angkatan 2017, 2018, dan 2019. Menurut Arikunto (dalam Hobsi, F, dkk 2019:153) jika jumlah populasi kurang dari 100 orang, maka jumlah sampelnya diambil secara keseluruhan, jika jumlah populasi lebih dari 100 orang, jumlah sampel bisa diambil $10 \%-15 \%$ atau 20\%-25\%. Pengumpulan data menggunakan teknik komunikasi langsung dengan angket sebagai alat pengumpulan data. Kategori yang digunakan dalam penelitian ini yaitu : Kurang Baik (KB), Cukup Baik (CB), Baik (B) dan Sangat Baik (SB) dengan skor $\mathrm{KB}=1, \mathrm{CB}=2, \mathrm{~B}=3$ dan $\mathrm{SB}$ $=4$.

Analisis data dilakukan dengan menghitung rata-rata kepuasan yang dirasakan oleh mahasiswa terhadap aspek berwujud (tangibles), kehandalan (reliability), daya tanggap (responsivencess), keyakinan (assurance), dan empati (empaty) dengan menggunakan google form. Dengan menggunakan rumus perhitungan statistik mean (rata-rata) dan persentase.

\section{Tabel 1 Kategori Penilaian}

Kategori Interval 




\section{HASIL DAN PEMBAHASAN}

Hasil penelitian diperoleh melalui angket yang disebarkan melalui google form kepada mahasiswa program studi PPKn FIS UNP yang dijadikan sampel. Hasil penelitian yang telah dihitung menggunakan nilai atau rata-rata skor untuk menentukan persepsi mahasiswa terhadap pelayanan program studi PPKn FIS UNP. Persepsi yang diteliti dalam penelitian ini yaitu persepsi mahasiswa terhadap pelayanan akademik dan pelayanan administrasi.

\section{Persepsi Mahasiswa terhadap Pelayanan Akademik Program Studi PPKn FIS UNP}

Tampubolon (dalam Suffiyah, A 2011:86), mengatakan bahwa layanan akademik memiliki porsi yang sangat besar dalam layanan pendidikan. Layanan akademik yaitu layanan yang banyak berkaitan langsung dengan mahasiswa, sehingga perguruan tinggi dalam memberikan layanan akademik harus berusaha memahami dan memenuhi kebutuhan mahasiswa serta berakhir pada persepsi mahasiswa. Layanan akademik yang berkualitas akan memeberikan kepuasan pada mahasiswa.

Parasuraman dalam Purnama (dalam Rinala, I N, dkk, 2013) menyebutkan bahwa ada lima dimensi kualitas pelayanan yaitu : tangible (bukti fisik), reliability (kehandalan), responsiveness (daya tanggap), assurance (jaminan) dan emphaty (empati).

Bekrikut persepsi mahasiswa terhadap pelayanan akademik program studi PPKn FIS UNP dideskripsikan dalam tabel berikut :

Tabel : 2 Aspek Tangible (sarana dan prasarana pendidikan)

\begin{tabular}{|c|l|c|c|c|}
\hline No & \multicolumn{1}{|c|}{ Aspek yang diukur } & Rata- & $\%$ & Kategori \\
\hline 1. & $\begin{array}{l}\text { Kebersihan, penataan dan } \\
\text { kenyamanan ruang kuliah }\end{array}$ & 3 & 75 & Cukup baik \\
\hline 2. & $\begin{array}{l}\text { Sarana pembelajaran yang } \\
\text { tersedia diruang kuliah }\end{array}$ & 3,1 & 77,5 & Baik \\
\hline 3. & $\begin{array}{l}\text { Sirkulasi udara diruang } \\
\text { perkuliahan }\end{array}$ & 2,8 & 70 & Cukup baik \\
\hline 4. & $\begin{array}{l}\text { Ketersediaan literatur diruang } \\
\text { baca yang mendukung mata } \\
\text { kuliah }\end{array}$ & 2,8 & 70 & Cukup baik \\
\hline 5. & $\begin{array}{l}\text { Ketersediaan fasilitas ibadah } \\
\text { yang dapat dipergunakan oleh } \\
\text { mahasiswa }\end{array}$ & 2,8 & 70 & Cukup baik \\
\hline 6. & $\begin{array}{l}\text { Ketersediaan ruang terbuka } \\
\text { untuk diskusi }\end{array}$ & 3 & 75 & Cukup baik \\
\hline 7. & $\begin{array}{l}\text { Ketersediaan fasilitas kamar } \\
\text { mandi kecil }\end{array}$ & 2,6 & 65 & Cukup baik \\
\hline 8. & $\begin{array}{l}\text { Ketersediaan parkir untuk } \\
\text { kendaraan bermotor }\end{array}$ & 3,1 & 77,5 & Baik \\
\hline & \multicolumn{1}{|c|}{ Rata-rata } & 72,5 & Baik \\
\hline
\end{tabular}

Dari hasil tabel diatas, dapat diketahui bahwa persepsi mahasiswa terhadap aspek tangible (kualitas sarana dan prasarana pendidikan) yaitu cukup baik dengan persentase 72,5\%. Aspek yang paling rendah yaitu ketersediaan fasilitas kamar mandi kecil sebesar $65 \%$ dengan kategori cukup baik sedangkan aspek yang paling tinggi yaitu sarana pembelajaran diruang kuliah dan ketersediaan parkir untuk kendaraan bermotor sebesar 77,5\% dengan kategori baik. Zeithami dan dan Bitner (2004) menyatakan bahwa, wujud atau bukti fisik adalah suatu hal yang secara nyata turut mempengaruhi kepuasan untuk menggunakan jasa yang ditawarkan. 
Tabel 3 Aspek Reliability (kehandalan dosen dalam perkuliahan)

\begin{tabular}{|c|c|c|c|c|}
\hline No & Aspek yang diukur & $\begin{array}{c}\text { Rata- } \\
\text { rata }\end{array}$ & $\%$ & $\begin{array}{l}\text { Kat } \\
\text { egor } \\
i\end{array}$ \\
\hline 1. & $\begin{array}{l}\text { Ketepatan waktu dosen } \\
\text { dalam memulai } \\
\text { perkuliahan }\end{array}$ & 3,5 & 87,5 & Baik \\
\hline 2. & $\begin{array}{l}\text { Kejelasan dosen } \\
\text { menyampaikan rencana } \\
\text { perkuliahan, aturan dan } \\
\text { evaluasi yang akan } \\
\text { dilaksanakan pada } \\
\text { pertemuan pertama }\end{array}$ & 3,5 & 87,5 & Baik \\
\hline 3. & $\begin{array}{l}\text { Ketepatan waktu dosen } \\
\text { dalam mengakhiri } \\
\text { perkuliahan }\end{array}$ & 3,5 & 87,5 & Baik \\
\hline 4. & $\begin{array}{l}\text { Pemberian bahan ajar } \\
\text { (handout, e-modul) oleh } \\
\text { dosen untuk } \\
\text { melengkapi materi yang } \\
\text { diberikan }\end{array}$ & 3,3 & 82,5 & Baik \\
\hline 5. & $\begin{array}{l}\text { Penyerahan hasil } \\
\text { koreksi tugas-tugas } \\
\text { disertai umpan balik } \\
\text { oleh dosen }\end{array}$ & 3,3 & 82,5 & Baik \\
\hline 6. & $\begin{array}{l}\text { Penyerahan hasil UTS } \\
\text { dan UAS pada } \\
\text { mahasiswa oleh dosen }\end{array}$ & 3,1 & 77,5 & Baik \\
\hline 7. & $\begin{array}{l}\text { Jumlah pertemuan } \\
\text { dosen dalam } \\
\text { menyampaikan materi } \\
\text { perkuliahan (minimal } 12 \\
\text { kali pertemuan) }\end{array}$ & 3,5 & 87,5 & Baik \\
\hline & Rata-rata & 3,38 & 84,6 & Baik \\
\hline
\end{tabular}

\section{Aspek Reliability (kehandalan dosen dalam perkuliahan)}

Dari hasil tabel diatas, dapat diketahui bahwa persepsi mahasiswa terhadap aspek reliability (kehandalan dosen dalam perkuliahan) yaitu baik dengan persentase $84,6 \%$. Aspek yang paling rendah yaitu penyerahan hasil UTS dan UAS pada mahasiswa oleh dosen yaitu sebesar $77,5 \%$ dengan kategori baik. Berdasarkan temuan $\mathrm{M}$. Arief, A. Yahya Suryadinata (2010), Dwi Aryani, Febrina Rosita (2010) menyatakan keandalan adalah dimensi kualitas pelayanan yang berperan besar sebagai dasar dalam mengukur kepuasan mahasiswa.
Tabel 4 Aspek responsivenes (sikap tanggap dosen)

\begin{tabular}{|c|l|c|c|c|}
\hline $\begin{array}{c}\text { No } \\
.\end{array}$ & \multicolumn{1}{|c|}{ Aspek yang dinilai } & $\begin{array}{c}\text { Rata } \\
\text {-rata }\end{array}$ & $\%$ & $\begin{array}{c}\text { Kategor } \\
\text { i }\end{array}$ \\
\hline 1. & $\begin{array}{l}\text { Intensitas dosen untuk } \\
\text { ditemui dalam rangka } \\
\text { konsultasi akademik } \\
\text { atau konsultasi skripsi } \\
\text { dan artikel }\end{array}$ & 3,4 & 85 & Baik \\
\hline 2. & $\begin{array}{l}\text { Kecepatan dosen dalam } \\
\text { menanggapi } \\
\text { pertanyaan/permasalah } \\
\text { an mahasiswa }\end{array}$ & 3,5 & 87,5 & Baik \\
\hline \multicolumn{1}{|l|}{ Rata-rata } & 3,45 & $\begin{array}{c}86,2 \\
5\end{array}$ & Baik \\
\hline
\end{tabular}

Dari hasil tabel diatas, dapat diketahui bahwa persepsi mahasiswa terhadap aspek responsivenes (sikap tanggap dosen) yaitu baik dengan persentase $86,25 \%$. Parasuraman, et, al menyatakan daya tanggap sebagai salah satu dimensi utama dalam kualitas jasa.

Tabel 5 Aspek assurance (jaminan/perlakuan dosen kepada mahasiswa)

\begin{tabular}{|c|l|c|c|c|}
\hline $\begin{array}{c}\mathrm{N} \\
\text { o. }\end{array}$ & $\begin{array}{c}\text { Aspek yang } \\
\text { dinilai }\end{array}$ & $\begin{array}{c}\text { Rata- } \\
\text { rata }\end{array}$ & $\%$ & Kategori \\
\hline 1. & $\begin{array}{l}\text { Kemampuan } \\
\text { dosen dalam } \\
\text { mengarahka } \\
\text { n mahasiswa } \\
\text { menggunaka } \\
\text { n pendekatan } \\
\text { interdisiplin } \\
\text { dalam } \\
\text { pembelajaran }\end{array}$ & 3,5 & 87,5 & Baik \\
\hline 2. & $\begin{array}{l}\text { Kemampuan } \\
\text { dosen } \\
\text { mengarahka } \\
\text { n mahasiswa } \\
\text { memiliki } \\
\text { keterampilan } \\
\text { leadership } \\
\text { dan problem } \\
\text { solving }\end{array}$ & 3,5 & 87,5 & Baik \\
\hline 3. & $\begin{array}{l}\text { Kemampuan } \\
\text { dosen } \\
\text { mengarahka } \\
\text { n mahasiswa } \\
\text { menggunaka } \\
\text { n literatur } \\
\text { asing dan IT } \\
\text { dalam } \\
\text { pembelajaran }\end{array}$ & 3,4 & 85 & Baik \\
\hline 4. & $\begin{array}{l}\text { Kemampuan } \\
\text { dosen } \\
\text { mengarahka } \\
\text { n mahasiswa }\end{array}$ & 3,5 & 87,5 & Baik \\
\hline
\end{tabular}




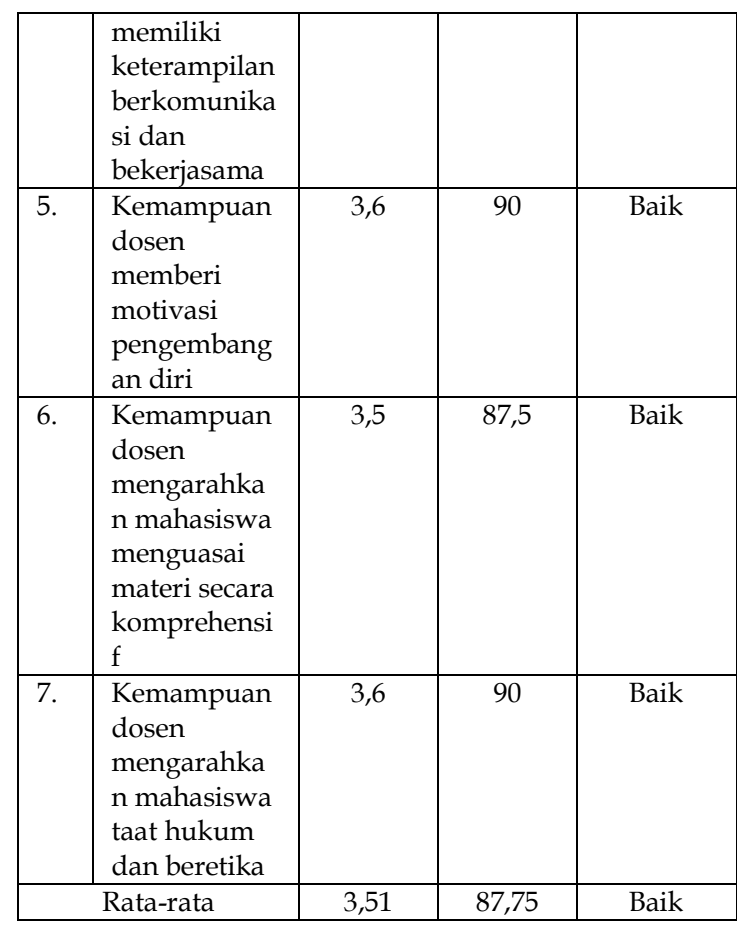

Dari tabel diatas, dapat diketahui bahwa persepsi mahasiswa terhadap aspek assurance (jaminan/perlakuan dosen kepada mahasiswa) yaitu baik dengan persentase 87,75\%. Aspek terendah yaitu Kemampuan dosen mengarahkan mahasiswa menggunakan literatur asing dan IT dalam pembelajaran sebesar 85\% dengan kategori baik. Sedangkan aspek paling tinggi yaitu kemampuan dosen memberi motivasi pengembangan diri dan kemampuan dosen mengarahkan mahasiswa taat hukum dan beretika sebesar $90 \%$ dengan kategori baik.

Dwi Aryani, Febrina Rosita (2010), Skoglan dan Siguaw, J, A. (2004) menyatakan assurance merupakan faktor kualitas pelayanan pada bidang jasa pendidikan.

Tabel 6 Aspek emphaty (pemahaman dosen terhadap kepentingan mahasiswa)

\begin{tabular}{|c|c|c|c|c|}
\hline No. & Aspek yang dinilai & $\begin{array}{c}\text { Rata- } \\
\text { rata }\end{array}$ & $\%$ & Kategori \\
\hline
\end{tabular}

\begin{tabular}{|l|l|c|c|c|}
\hline 1. & $\begin{array}{l}\text { Kesediaan dosen } \\
\text { membantu } \\
\text { mahasiswa yang } \\
\text { bermasalah dalam } \\
\text { bidang akademik }\end{array}$ & 3,4 & 85 & Baik \\
\hline 2. & $\begin{array}{l}\text { Kemudahan dosen } \\
\text { untuk dihubungi } \\
\text { melalui telepon, } \\
\text { email dan } \\
\text { sebagainya }\end{array}$ & 3,4 & 85 & Baik \\
\hline 3. & $\begin{array}{l}\text { Keterbukaan dan } \\
\text { sikap kooperatif } \\
\text { dosen dengan } \\
\text { mahasiswa }\end{array}$ & 3,5 & 87,5 & Baik \\
\hline \multicolumn{2}{|l|}{} & 3,43 & 85,8 & Baik \\
\hline
\end{tabular}

Dari tabel diatas, dapat kita ketahui bahwa persepsi mahasiswa terhadap aspek emphaty (pemahaman dosen terhadap kepentingan mahasiswa) yaitu baik dengan persentase 85,8. Dwi Aryani, Febrina Rosita (2010) menyatakan empati yaitu dimensi yang sangat berpengaruh terhadap kualitas pelayanan. Semakin besar empati yang diberikan kepada mahasiswa maka kualitas pelayanan akademik dinilai semakin baik.

Dari hasil tabel 2,3,4,5dan 6 maka dapat diketahui bagaimana persepsi mahasiswa terhadap pelayanan pendidikan program studi PPKn FIS UNP yang dinyatakan pada tabel berikut:

Tabel 7 Rekapitulasi persepsi mahasiswa terhadap pelayanan akademik dilihat dari kelima aspek pelayanan

\begin{tabular}{|c|c|c|c|c|}
\hline No. & Aspek Pelayanan & $\begin{array}{c}\text { Rata- } \\
\text { rata }\end{array}$ & $\%$ & Kategori \\
\hline 1. & $\begin{array}{l}\text { Tangible (Sarana dan } \\
\text { prasarana } \\
\text { pendidikan) }\end{array}$ & 2,9 & 72,5 & $\begin{array}{c}\text { Cukup } \\
\text { baik }\end{array}$ \\
\hline 2. & $\begin{array}{l}\text { Reliability } \\
\text { (kehandalan dosen } \\
\text { dalam perkuliahan) }\end{array}$ & 3,38 & 84,6 & Baik \\
\hline 3. & $\begin{array}{l}\text { Responsivenes } \\
\text { (sikap tanggap } \\
\text { dosen) }\end{array}$ & 3,45 & 86,25 & Baik \\
\hline 4. & $\begin{array}{l}\text { Assurance } \\
\text { (jaminan/perlakuan } \\
\text { dosen pada } \\
\text { mahasiswa) }\end{array}$ & 3,51 & 87,75 & Baik \\
\hline 5. & Aspek Emphaty & 3,43 & 85,8 & Baik \\
\hline
\end{tabular}




\begin{tabular}{|c|l|l|l|l|}
\hline & $\begin{array}{l}\text { (Pemahaman Dosen } \\
\text { terhadap } \\
\text { Kepentingan } \\
\text { Mahasiswa) }\end{array}$ & & & \\
\hline Rata-rata & 3,33 & 83,25 & Baik \\
\hline
\end{tabular}

Dari hasil tabel diatas dapat diketahui bahwa, dari lima aspek yang dilihat maka aspek yang paling rendah yaitu aspek tangible (sarana dan prasarana pendidikan) sebesar $72,5 \%$ dengan kategori cukup baik sedangkan aspek yang paling tinggi yaitu aspek assurance (jaminan/perlakuan dosen kepada mahasiswa) sebesar 87,86\% dengan kategori baik. Secara keseluruhan, dapat disimpulkan bahwa persepsi mahasiswa terhadap pelayanan akademik berada pada kategori baik dengan persentase $83,25 \%$.

\section{Persepsi Mahasiswa terhadap Pelayanan Administrasi Program Studi PPKn FIS UNP}

Hasil penelitian sesuai dengan Kotler (dalam Rohani \& Rianto Hadi 2017:183) yang menyatakan bahwa ada lima dimensi kualitas pelayanan yaitu : berwujud (tangible) : penampilan fasilitas fisik, peralatan, personel dan media komunikasi, kepercayaan atau keandalan (reliability) : kemampuan untuk melaksanakan pelayanan yang dijanjikan dengan tepat dan terpercaya, daya tanggap (responsiveness) : kemampuan untuk membantu pelanggan dan memberikan jasa dengan cepat tanggap, keyakinan (assurance) : pengetahuan atua kesopanan pustakawan serta kemampuan mereka untuk menimbulkan rasa kepercayaan dan keyakinan pada mahasiswa, dan empati (emphaty) : peduli, membrikan perhatian pribadi pada pelanggan.

Hasil penelitian Ackerman (dalam Iradawati S,N 2018:20) kualitas administrasi berpengaruh terhadap loyalitas mahasiswa. Menurut Arambewela dan Hall (dalam Iradawati S,N 2018:20) kualitas administrasi berpengaruh terhadap kepuasan mahasiswa.

Kualitas layanan administrasi merupakan salah satu strategi untuk menciptakan kepuasan konsumen. Pendidikan berkualitas harusnya menjamin semua strata pendidikan termasuk dalam suatu sistem.

Berikut persepsi mahasiswa terhadap pelayanan administrasi program studi PPKn FIS UNP dideskripsikan dalam tabel berikut :

Tabel 8 Aspek tangibles (sarana dan prasarana layanan administrasi)

\begin{tabular}{|l|l|c|c|c|}
\hline No. & Aspek yang dinilai & $\begin{array}{c}\text { Rata- } \\
\text { rata }\end{array}$ & $\%$ & Kategori \\
\hline 1. & $\begin{array}{l}\text { Tatanan } \\
\text { administrasi rapi } \\
\text { dan teratur }\end{array}$ & 3,3 & 82,5 & Baik \\
\hline 2. & $\begin{array}{l}\text { Ruang pelayanan } \\
\text { dan ruang tunggu } \\
\text { nyaman }\end{array}$ & 3,1 & 77,5 & Baik \\
\hline 3. & $\begin{array}{l}\text { Kantor tertata } \\
\text { dengan bersih dan } \\
\text { rapi }\end{array}$ & 3,5 & 87,5 & Baik \\
\hline & $\quad$ Rata-rata & 3,3 & 82,5 & Baik \\
\hline
\end{tabular}

Dari tabel diatas, dapat diketahui bahwa persepsi mahasiswa terhadap aspek tangible (sarana dan prasarana layanan administarsi) yaitu baik dengan persentase 82,5. Aspek yang paling rendah yaitu ruang pelayanan dan ruang tunggu nyaman sebesar $77,5 \%$ dengan kategori baik. Sedangkan aspek tertinggi yaitu kantor tertata dengan bersih dan rapi sebesar 87,5\% dengan kategori baik.

Tabel 9 Aspek Reliability (Kehandalan Staf Administrasi dalam Pelayanan)

\begin{tabular}{|l|l|c|c|c|}
\hline No. & Aspek yang dinilai & $\begin{array}{c}\text { Rata- } \\
\text { rata }\end{array}$ & $\%$ & Kategori \\
\hline 1. & $\begin{array}{l}\text { Memiliki } \\
\text { kemampuan dan } \\
\text { pengetahuan dalam } \\
\text { memberikan } \\
\text { pelayanan }\end{array}$ & 3,3 & 82,5 & Baik \\
\hline
\end{tabular}




\begin{tabular}{|l|l|c|c|c|}
\hline 2. & $\begin{array}{l}\text { Prosedur } \\
\text { penyampain } \\
\text { informasi jelas dan } \\
\text { mudah dimengerti }\end{array}$ & 3,3 & 82,5 & Baik \\
\hline 3. & $\begin{array}{l}\text { Prosedur pelayanan } \\
\text { tidak berbelit-belit, } \\
\text { cepat dan tepat }\end{array}$ & 3,2 & 80 & Baik \\
\hline 4. & $\begin{array}{l}\text { Memberikan } \\
\text { pelayanan } \\
\text { memuaskan sesuai } \\
\text { kebutuhan }\end{array}$ & 3,3 & 82,5 & Baik \\
\hline 5. & $\begin{array}{l}\text { Menunjukkan } \\
\text { disiplin kerja }\end{array}$ & 3,4 & 85 & Baik \\
\hline & Rata-rata & 3,3 & 82,5 & Baik \\
\hline
\end{tabular}

Dari tabel diatas, dapat diketahui bahwa persepsi mahasiswa terhadap aspek reliability (kehandalan staf administrasi dalam pelayanan) yaitu baik dengan persentase $82,5 \%$. Aspek yang paling rendah yaitu prosedur pelayanan tidak berbelit-belit, cepat dan tepat sebesar 80\% dengan kategori baik. Sedangkan aspek tertinggi yaitu menunjukkan disiplin kerja dengan kategori baik.

Tabel 10 Aspek Responsivenes (sikap tanggap staf administrasi dalam pelayanan)

\begin{tabular}{|l|l|c|c|c|}
\hline No. & Aspek yang dinilai & $\begin{array}{c}\text { Rata- } \\
\text { rata }\end{array}$ & $\%$ & Kategori \\
\hline 1. & $\begin{array}{l}\text { Memberikan } \\
\text { tanggapan terhadap } \\
\text { permohonan } \\
\text { pelayanan }\end{array}$ & 3,4 & 85 & Baik \\
\hline 2. & $\begin{array}{l}\text { Cepat memberikan } \\
\text { tanggapan apabila } \\
\text { terjadi kesalahan } \\
\text { pada hasil } \\
\text { pelayanan }\end{array}$ & 3,3 & 82,5 & Baik \\
\hline 3. & $\begin{array}{l}\text { Tidak membiarkan } \\
\text { mahasiswa } \\
\text { menunggu antrian } \\
\text { terlalu lama }\end{array}$ & 3,1 & 77,5 & Baik \\
\hline 4. & $\begin{array}{l}\text { Komunikasi } \\
\text { pelayanan } \\
\text { berlangsung baik }\end{array}$ & 3,3 & 82,5 & Baik \\
\hline \multicolumn{2}{|l|}{ Rata-rata } & 3,3 & 82,5 & Baik \\
\hline
\end{tabular}

Dari tabel diatas, dapat diketahui bahwa persepsi mahasiswa terhadap aspek responsivenes (sikap tanggap staf administrasi dalam pelayanan) yaitu baik dengan persentase $82,5 \%$. Aspek yang paling rendah yaitu tidak membiarkan mahasiswa menunggu antrian terlalu lama sebesar 77,5\% dengan kategori baik. Sedangkan aspek tertinggi yaitu memberikan tanggapan terhadap permohonan pelayanan sebesar $85 \%$ dengan kategori baik.

Tabel 11 Aspek Assurance (jaminan/perlakuan staf administrasi pada mahasiswa)

\begin{tabular}{|l|l|c|c|c|}
\hline No. & \multicolumn{1}{|c|}{$\begin{array}{c}\text { Aspek yang } \\
\text { dinilai }\end{array}$} & $\begin{array}{c}\text { Rata- } \\
\text { rata }\end{array}$ & $\%$ & Kategori \\
\hline 1. & $\begin{array}{l}\text { Memiliki sikap } \\
\text { sopan, jujur dan } \\
\text { dapat dipercaya }\end{array}$ & 3,5 & 87,5 & Baik \\
\hline 2. & $\begin{array}{l}\text { Memberikan } \\
\text { kemudahan } \\
\text { akses dalam } \\
\text { pelayanan }\end{array}$ & 3,4 & 85 & Baik \\
\hline & Rata-rata & 3,45 & 86,25 & Baik \\
\hline
\end{tabular}

Dari tabel diatas, dapat diketahui bahwa persepsi mahasiswa terhadap aspek assurance (jaminan/perlakuan staf adminstrasi pada mahasiswa) yaitu baik dengan persentase $86,25 \%$.

Tabel 12 Aspek Emphaty (pemahaman staf adminitrasi terhadap kepentingan mahasiswa)

\begin{tabular}{|l|l|c|c|c|}
\hline No. & Aspek yang dinilai & $\begin{array}{c}\text { Rata- } \\
\text { rata }\end{array}$ & $\%$ & Kategori \\
\hline 1. & $\begin{array}{l}\text { Memberikan } \\
\text { perhatian dan } \\
\text { saran yang baik } \\
\text { bagi mahasiswa }\end{array}$ & 3,4 & 85 & Baik \\
\hline 2. & $\begin{array}{l}\text { Memberikan } \\
\text { perlakuan yang } \\
\text { sama pada } \\
\text { mahasiswa }\end{array}$ & 3,2 & 80 & Baik \\
\hline & Rata-rata & 3,3 & 82,5 & Baik \\
\hline
\end{tabular}

Dari tabel diatas, dapat diketahui bahwa persepsi mahasiswa terhadap aspek emphaty (pemahaman staf admnistrasi pada mahasiswa) yaitu baik dengan persentase $82,5 \%$. 
Dari hasil tabel 8,9,10,11 dan 12 diatas, maka dapat diketahui bagaimana persepsi mahasiswa terhadap pelayanan administrasi program studi PPKn FIS UNP yang dinyatakan pada tabel berikut$$
\text { : }
$$

\section{Tabel 13 Rekapitulasi persepsi mahasiswa terhadap pelayanan administrasi dari kelima aspek pelayanan}

\begin{tabular}{|c|l|c|c|c|}
\hline No. & \multicolumn{1}{|c|}{ Aspek Pelayanan } & $\begin{array}{c}\text { Rata- } \\
\text { rata }\end{array}$ & $\%$ & $\begin{array}{c}\text { Kate } \\
\text { gori }\end{array}$ \\
\hline 1. & $\begin{array}{l}\text { Aspek tangibles (sarana } \\
\text { dan prasarana layanan } \\
\text { administrasi) }\end{array}$ & 3,3 & 82, & Baik \\
\hline 2. & $\begin{array}{l}\text { Aspek reliability } \\
\text { (kehandalan staf } \\
\text { administrasi dalam } \\
\text { pelayanan) }\end{array}$ & 3,3 & 82, & Baik \\
\hline 3. & $\begin{array}{l}\text { Aspek responsivenes } \\
\text { (sikap tanggap staf } \\
\text { administrasi dalam } \\
\text { pelayanan) }\end{array}$ & 3,3 & 82, & Baik \\
\hline 4. & $\begin{array}{l}\text { Aspek assurance } \\
\text { (jaminan/perlakuan staf } \\
\text { administrasi pada } \\
\text { mahasiswa) }\end{array}$ & 3,45 & 86, & Baik \\
\hline 5. & $\begin{array}{l}\text { Aspek emphaty } \\
\text { (pemahaman staf } \\
\text { adminitrasi terhadap } \\
\text { kepentingan mahasiswa) }\end{array}$ & 3,3 & 82, & Baik \\
\hline & $\begin{array}{l}\text { Rata-rata } \\
\text { Baik }\end{array}$ & 5 & \\
\hline & & 33 & 25 & \\
\hline
\end{tabular}

Dari hasil tabel diatas, maka dapat diketahui bahwa dari lima aspek yang dilihat maka aspek yang paling tinggi yaitu aspek assurance (jaminan/perlakuan staf administrasi pada mahasiswa) sebesar $86,25 \%$ dengan kategori baik. Secara keseluruhan, dapat disimpulkan bahwa persepsi mahasiswa terhadap pelayanan adminisntasi program studi PPKn FIS UNP berada pada kategori baik dengan persentase $83,25 \%$.

Dari hasil tabel rekapitulasi pelayanan akademik (tabel 7) dan pelayanan administrasi (tabel 13) diatas, maka dapat ditentukan rekapitulasi persepsi mahasiswa terhadap pelayanan program studi PPKn FIS UNP sebagai berikut :

Tabel 14 Rekapitulasi persepsi mahasiswa terhadap pelayanan program studi PPKn FIS UNP

\begin{tabular}{|c|l|c|c|c|}
\hline No & $\begin{array}{c}\text { Pelayanan } \\
\text { program studi } \\
\text { PPKn }\end{array}$ & $\begin{array}{c}\text { Rata- } \\
\text { rata }\end{array}$ & $\%$ & Kategori \\
\hline 1. & $\begin{array}{l}\text { Pelayanan } \\
\text { akademik }\end{array}$ & 3,33 & 83,25 & Baik \\
\hline 2. & $\begin{array}{l}\text { Pelayanan } \\
\text { admnistrasi }\end{array}$ & 3,33 & 83,25 & Baik \\
\hline \multicolumn{2}{|l|}{ Rata-rata } & 3,33 & 83,25 & Baik \\
\hline
\end{tabular}

Dari hasil tabel diatas, maka didapatkan rata-rata keseluruhan mengenai persepsi mahasiswa terhadap pelayanan program studi PPKn FIS UNP yaitu tingkat capaian $83,25 \%$ dengan kategori baik.

\section{PENUTUP}

Berdasarkan analisa data dari hasil penelitian dan pembahasan yang telah dikemukakan, maka diambil kesimpulan mengenai persepsi mahasiswa terhadap pelayanan PPKn FIS UNP sebagai berikut :

\section{Pelayanan Akademik}

Persepsi mahasiswa terhadap pelayanan akademik program studi PPKn FIS UNP berada pada kategori baik dengan tingkat capaian $83,25 \%$ dengan rincian sebagai berikut :

a. Aspek tangible (sarana dan prasarana pendidikan) sebesar $72,5 \%$ dengan kategori cukup baik.

b. Aspek reliability (kehandalan dosen dalam perkuliahan) sebesar $84,6 \%$ dengan kategori baik.

c. Aspek responsivenes (sikap tanggap dosen) sebesar 86,25\% dengan kategori baik. 
d. Aspek assurance (jaminan/ perlakuan dosen pada mahasiswa) sebesar 87,86\% dengan kategori baik.

e. Aspek emphaty (pemahaman dosen terhadap kepentingan mahasiswa) sebesar 85,8\% dengan kategori baik

\section{Pelayanan Administrasi}

Persepsi mahasiswa terhadap pelayanan administrasi program studi PPKn FIS UNP berada pada kategori baik dengan tingkat capaian $83,25 \%$ dengan rincian sebagai berikut :

a. Aspek tangible (sarana dan prasarana layanan administrasi) sebesar $82,5 \%$ dengan kategori baik.

b. Aspek reliability (kehandalan staf administrasi dalam pelayanan) sebesar $82,5 \%$ denga kategori baik.

c. Aspek responsivenes (sikap tanggap staf administrasi dalam pelayanan) sebesar $81,9 \%$ dengan kategori baik.

d. Aspek assurance (jaminan/ perlakuan staf administasi pada mahasiswa) sebesar $86,25 \%$ dengan kategori baik.

e. Aspek emphaty (pemahaman staf administrasi terhadap kepentingan mahasiswa sebesar 82,5\% dengan kategori baik.

Dari rata-rata hasil persentase persepsi mahasiswa dilihat dari indikator pelayanan akademik dengan tingkat capaian 83,25 dan pelayanan administrasi dengan tingkat capaian yang sama yaitu $83,25 \%$, maka didapatkan kesimpulan rata-rata secara keseluruhan mengenai persepsi mahasiswa terhadap pelayanan program studi PPKn FIS UNP yaitu $83,25 \%$ dengan kategori baik.
Adaptasi Kemendikbud, 2013:31. Metode penelitian. Digilib.unila.ac.id.

Darwyansyah, D. (2017). Pengukuran dan penilaian kualitas pelayanan perguruan tinggi. Saintifika islamica: Jurnal Kajian Keislaman, 1(02), 19-37.

Hobsi, F., Sunaryo, H., \& ABS, M. K. (2019). Pengaruh Motivasi dan Kompensasi terhadap Kinerja Karyawan UD. CJDW METESEH KOTA SEMARANG. Jurnal Ilmiah Riset Manajemen, 8(17).

Husnayetti, H. (2012). Tingkat Kepuasan Mahasiswa Dan Proses Belajar Mengajar Di Perguruan Tinggi X. Liquidity, 1(2), 115-124.

Iradawati, S. N. (2019). Pengaruh Kualitas Layanan Adminstrasi Dan Fisik Kampus Terhadap Kepuasan Mahasiswa Universitas Yos Sudarso Surabaya. Management $\mathcal{E}$ Accounting Research Journal, 3(1).

Rinala, I. N., Yudana, I. M., \& Natajaya, I. N. (2013). Pengaruh kualitas pelayanan akademik terhadap kepuasan dan loyalitas mahasiswa pada Sekolah Tinggi Pariwisata Nusa Dua Bali. Jurnal Administrasi Pendidikan Indonesia, 4(1).

Rohani, R., \& Rianto, H. (2017). Analisis tingkat kepuasan mahasiswa pada pelayanan program studi PPKN. Sosial Horizon: Jurnal Pendidikan Sosial, 4(2), 178-187.

Sufiyyah, A. (2011). Pengaruh Kualitas Layanan Akademik dan Birokrasi terhadap Kepuasan Mahasiswa. Jurnal Ilmiah Aset, 13(2), 85-93.

\section{DAFTAR PUSTAKA}


305 | persepsi mahasiswa

Udjang, R., \& Subarjo, S. (2019). Analisis Tingkat Kepuasan Mahasiswa Pada Kualitas Layanan Universitas
Mercu Buana Yogyakarta. Jurnal Perilaku dan Strategi Bisnis, 7(1), 6475. 